\title{
A questão previdenciária
}

\author{
Fabio Giambiagi* \\ Isabela Esterminio
}

Entre 1988 e 2006, a despesa do INSS terá mais do que triplicado o seu peso relativo no PIB, atingindo quase $8 \%$ deste. A pressão crescente da relação despesa do INSS/PIB explica-se por quatro razões. Em primeiro lugar, pelo "efeito denominador": o baixo crescimento do PIB é certamente uma das razões que hipertrofia a importância relativa dessa despesa, em um contexto em que o numerador, por razões demográficas, cresceu em torno de $4 \%$ a.a. A segunda razão decorre do impacto do salário mínimo (SM), que desde a metade da década de 1990 tem tido seu valor elevado muito além dos índices de preço, fazendo com que os benefícios do INSS tenham tido expressivo ganho real de renda. A terceira é a benevolência de nossa legislação, que permite a existência de aposentadorias precoces. Por último, a partir da década atual, entrou em jogo um elemento novo: o aumento expressivo do número de auxílio-doença. O número de indivíduos que recebia este benefício triplicou de 2000 para 2005.

As propostas de reforma referentes à Previdência Social para equacionar o problema representado pelo gasto crescente com aposentadorias e pensões inserem-se na categoria conhecida na literatura como "reformas paramétricas". Simplificadamente, elas mantêm o "status quo", sem mudar o regime, mas introduzem mudanças significativas nas regras de aposentadoria. Ao final de certo período de transição, cada indivíduo teria em perspectiva três possibilidades alternativas de recebimento de benefício, com condicionalidades cruzadas:

i) Aposentadoria por idade: corresponde formalmente ao regime que vigora atualmente, porém com uma idade maior e um requisito mínimo de tempo contributivo, de 25 anos (atualmente, é de apenas 12,5 anos);

ii) Aposentadoria por tempo de contribuição: representa o regime atual, porém, da mesma forma que em (i), com mudanças importantes, especificamente pela existência de uma idade mínima para aposentadoria, como a estabelecida no serviço público após a reforma de 2003 (que não se aplica atualmente ao INSS); e

iii) Beneficio assistencial: conhecido como Lei Orgânica da Assistência Social (LOAS), porém com três diferenças em relação à prática atual: nas novas concessões,

\footnotetext{
* Economista do BNDES, cedido ao IPEA. Endereço eletrônico: fgiambia@ipea.gov.br

** Assistente de pesquisa IPEA. Endereço eletrônico: isabelaesterminio@gmail.com
} 
limitação a uma fração inferior a 100\% do benefício previdenciário mínimo e aumento da idade de exigibilidade.

Este artigo condensa em parte os argumentos expostos em Reforma das Instituições fiscais para a redução da despesa e da carga tributária e aumento da eficiência de Estado, de Fabio Giambiagi e Paulo Tafner, apresentado no III Encontro CODIMEC de Mercado de Capitais, São Paulo, abril 2006.

Nessas condições, o indivíduo poderia se aposentar por idade, porém com um requisito mínimo elevado de período contributivo; por tempo de contribuição, mas com idade mínima; ou só receber o LOAS, mas limitado a um valor inferior ao atual e a uma idade maior. Isso definiria "trade offs" adequados e aproximaria o sistema dos parâmetros observados em outros países.

Concretamente, sugere-se uma reforma da Previdência Social baseada em 8 componentes, quase todos com necessidade de mudança constitucional:

a) Adoção de idade mínima igual à vigente para o funcionalismo, de 60 anos para os homens, para a conquista do direito à aposentadoria por tempo de contribuição, a ser adotada após um período de carência de alguns anos (não mais do que cinco anos), dando tempo a todos os indivíduos de se adaptar às novas regras;

b) Elevação progressiva da idade mínima, ao longo de um período de 10 anos, contando a partir da vigência da idade inicial de 60 anos, até 65 anos para os homens;

c) Elevação da idade de aposentadoria para quem se aposenta por idade, até 67 anos para os homens, após um processo de transição de dez anos, em relação aos 65 anos atuais, com acréscimo de um ano a cada cinco anos até os citados 67;

d) Aumento do período contributivo para quem se aposenta por idade (hoje de 12,5 anos) até 30 anos, mantida a regra atual de elevação de seis meses por ano, prevista para ser concluída em 2011 com 15 anos, para 25 anos, estendendo a transição desse item até 2031;

e) Redução da diferença de requisito em número de anos entre homens e mulheres, atualmente de 5 anos, em 1 ano a cada 5 anos a partir de 2010, até o limite de 2 anos no caso de quem se aposenta por idade e eliminando essa diferença para a exigência de período contributivo mantida a regra de redução de 1 ano a cada 5 anos, completando a transição em 2020 para quem se aposenta por idade e em 2030 para quem se aposenta por tempo de contribuição (com 35 anos para homens e mulheres);

f) Extinção dos regimes especiais dos professores e dos indivíduos que moram no meio rural, adotando a mesma regra de redução da diferença do item (e); 
g) Mudança, nas novas concessões, das regras do LOAS, com aumento gradativo na proporção de 1 ano a cada 2 anos da idade de elegibilidade de 65 para 70 anos; e redução imediata do valor do benefício para os novos beneficiários de $100 \%$ para $75 \%$ do benefício previdenciário mínimo; e

h) Desvinculação do piso previdenciário em relação ao salário mínimo, indexando o valor de todos os benefícios - inclusive o piso - ao IPCA.

Adicionalmente, propõe-se adotar regras diferenciadas para os futuros entrantes no sistema. Isto implicaria dividir a população em 3 grandes grupos:

- Atuais beneficiados (aposentadorias, pensões e benefícios de LOAS e Rendas Mensais Vitalícias): os direitos adquiridos seriam respeitados, não havendo mudança nenhuma;

- Atuais ativos: passariam pelo regime de transição, sendo mais ou menos afetados em função do tempo restante que falta para o usufruto do benefício;

- Futuros entrantes: aqueles que vierem a contribuir para o sistema a partir da aprovação das novas regras.

Embora as medidas propostas sejam controversas, elas têm uma justificativa clara. No caso da adoção de uma idade mínima, decorre do fato de que um contingente grande de indivíduos que faz jus ao benefício por tempo de contribuição continua se aposentando com idades que são comparativamente precoces em relação ao resto do mundo, somada à analogia com a situação do serviço público, onde o princípio da idade mínima já foi consagrado. Não há justificativa alguma para não fazer o mesmo no INSS.

No que diz respeito à aposentadoria por idade, os limites atuais são adequados, mas não mais o serão daqui a 10 ou 20 anos. Considerando que a expectativa de sobrevida nessas faixas não é substancialmente diferente em relação aos países mais avançados, é razoável que o país comece a pensar em estender a idade de aposentadoria para níveis maiores aos prevalecentes até agora, como vem ocorrendo em diversos países do mundo. Ao mesmo tempo, o período contributivo a ser exigido - mantido o ritmo atual de elevação já definido em Lei, chegará a 15 anos em 2011 - para se aposentar por idade é irrisório em termos internacionais, não havendo razão para não se elevar esse requisito para pelo menos 25 anos.

A redução do diferencial entre homens e mulheres obedece ao agravamento progressivo associado ao desequilíbrio previdenciário causado pelas regras de acesso à aposentadoria feminina. Com o aumento da participação das mulheres no mercado de trabalho, verificado no pós-guerra, tal dinâmica se transfere com defasagem de algumas 
décadas para a composição do fluxo de novas aposentadorias, o que significa que o fato de as mulheres se aposentarem antes acaba pesando cada vez mais nas contas. Ao mesmo tempo, a experiência internacional valida a tendência à redução do diferencial entre homens e mulheres, diferencial esse que, embora em parte justificável, não se verifica na grande maioria dos países. Uma alternativa "salomônica" que tentasse adaptar o Brasil à realidade mundial, ao mesmo tempo acolhendo os argumentos ligados à necessidade de compensar as mulheres pela existência da chamada "dupla jornada de trabalho", seria então preservar a existência de um diferencial, porém diminuindo ele de 5 para 2 anos.

A razão para a eliminação do regime especial dos aposentados do meio rural e dos professores é que, contrariamente ao caso das mulheres, em que há certa justificativa para a diferenciação comparativamente aos homens, nesses dois casos a diferenciação de requisito de idade não tem qualquer amparo razoável. No meio rural, porque ela já se dá nas condições contributivas, muito mais favoráveis. E, no caso dos professores, porque a categoria não preenche a condição de dano comprovado à saúde e prejuízo para a expectativa de vida, que é a base conceitual da existência de um direito de passagem precoce para a inatividade.

A mudança proposta nas regras de concessão do LOAS obedece a uma lógica clara: não faz sentido ter o mesmo benefício e ele ser concedido à mesma idade para quem contribuiu durante anos e para quem nunca contribuiu para o sistema. O conceito de benefício assistencial é uma conquista civilizatória, mas deve ser associado a uma estrutura de incentivos que premie mais quem contribui. Portanto, o benefício assistencial deve ser menor que o piso previdenciário e a idade de elegibilidade deve ser maior que a requerida para receber a aposentadoria.

A desvinculação entre o salário mínimo e o piso previdenciário evitaria a pressão sistemática que os aumentos do salário mínimo têm gerado ao longo dos últimos 12 anos, no sentido de elevar a relação entre o gasto do INSS e o PIB. A razão para a desvinculação é muito simples: o número de aposentados e pensionistas cresce em torno de $4 \%$ a.a. e o valor da folha de aposentados e pensionistas que recebem o piso previdenciário é da ordem de $1 / 3$ da despesa total do INSS. Portanto, na presença de aumentos reais do salário mínimo, sem a ocorrência de desvinculação, a despesa vai aumentar em termos reais mais do que $4 \%$ e se a economia não crescer a essa taxa, a relação despesa do INSS/PIB continuará crescendo indefinidamente, como vem fazendo desde 1988. Além disso, alterações do salário mínimo devem guardar relação com a dinâmica do mercado de trabalho e da produtividade do trabalho, o que, convenhamos, em nada deve afetar aqueles que estão em período pós-laboral. 
Por último, Barros e Carvalho (2005) mostram claramente que o efeito de aumentos do piso previdenciário é muito pequeno no combate à pobreza extrema. Quando o piso previdenciário aumenta, apenas $2 \%$ do adicional de renda gerada na economia beneficia as famílias extremamente pobres. A razão não é difícil de entender: é que, em linhas gerais, idosos que ganham um salário mínimo não pertencem a famílias extremamente pobres, uma vez que a linha de extrema pobreza se situa em um patamar inferior ao salário mínimo. Em outras palavras, aumentos do salário mínimo, transferidos ao piso previdenciário, são extremamente onerosos para as contas públicas e completamente ineficientes para atacar o problema da extrema pobreza e da desigualdade. Faz muito mais sentido focalizar os recursos adicionais em programas com um público-alvo melhor definido, como o Bolsa-Família.

\section{Referências Bibliográficas}

BARROS, R. P. de; CARVALHO, M. (2005). Salário minimo e distribuição de renda. IPEA, Seminários DIMAC, no 196. 
